\title{
TSH-Producing Pituitary Gland Carcinoma
}

National Cancer Institute

\section{Source}

National Cancer Institute. TSH-Producing Pituitary Gland Carcinoma. NCI Thesaurus.

Code C5965.

A rare, hormonally functioning or non-functioning pituitary gland adenocarcinoma that produces thyrotropin. 